\title{
BEHAVIOUR OF SALT DISTRIBUTION IN DRY SOILS
}

\author{
Angelo Sommella, Alessandro Santini, Gerardo Severino, Alessandro Comegna
}

\section{Introduction}

Salinization of the most upper soil layers represents a problem of fundamental importance to agricultural as well as environmental science. This mostly depends upon the highly transient water flow regime resulting from brief wetting, and very prolonged subsequent drying events. The complexity of transient, unsaturated flow and transport phenomena poses a significant obstacle to attaining reliable numerical solutions, and it has spurred an extensive search for analytical methods. Numerous approaches to solving the unsaturated flow equations have been suggested in the literature (e.g., $[9,15,16])$. Most of them apply to steady advection (e.g., [4, 2, 13, 10]). Dagan and Bresler [5] modelled one-dimensional solute transport under unsteady infiltration and redistribution based on a global approximation of flux during propagation of a step function water content. Although the real water content profiles do not follow a simple step geometry, it is assumed that the description of the flow field is adequate for predicting the rate of solute convection. Indelman et al. [12] further refined this model and obtained an analytical, approximate solution for flow and transport that preserves local mass balance everywhere in the profile. The model of Indelman et al. [12] was further investigated by Severino and Indelman [22], Lessoff and Indelman [13], and Severino et al. [23]. Natural soil heterogeneity may have a significant impact on flow and transport. Numerous studies have attempted to solve this complex problem by modelling the soil conductivity as a random spatial function, and dealing with weakly heterogeneous formations (e.g. [24, 25, 23, 11]). An approach not restricted by the assumption of weak heterogeneity was suggested by Dagan and Bresler [4]. They introduced

Paper received 10.01.2007; accepted 27.06.2007

Prof. Angelo Sommella, Full Professor; Prof. Alessandro SANtini, Full Professor; Eng. Gerardo Severino, Assistant Professor; Eng. Alessandro Comegna; Department of Agricultural Engineering and Agronomy, University of Naples, ITALY. the column model of flow and transport which represents shallow, three-dimensional infiltration as a collection of vertical tubes. This methodology has been applied in many field and theoretical studies (e.g., $[16,8,18,12,20,21,23])$.

In this study, we present an analytical solution for salt transport under intermittent water application (i.e. during infiltration and subsequent redistribution). This is achieved by assuming gravitational flow, and combining it with purely advective-transport. The main finding of our result permits to explain the typical phenomenon of soil salinization due to long drying periods.

\section{General solution to advective transport}

We consider one-dimensional salt transport in a semi-infinite domain $z>0$ where $z$ is depth (positive downward), and $z=0$ is the location of the soil surface. The initial saline distribution is given by $C(z, 0)=$ $C_{0}(z)$, where $C(z, t)$ is the concentration (mass of salt per volume of soil). Following many other Authors (e.g. $[6,12,23])$, we simplify computations by neglecting the effect of local dispersion. As a consequence, parcels of salt are advected downwards with the velocity $u=q / \theta$ according to the convection equation:

$$
\frac{\partial C}{\partial t}+u \frac{\partial C}{\partial z}=0
$$

being $q$ and $\theta$ are the flux and water content, respectively. Transport equation (1) is solved by the method of characteristics: along the characteristic line defined as:

$$
\frac{d z_{e}}{d t}=u\left(z_{r}, t\right)
$$

the saline parcel is determined by:

$$
C(z, l)=C_{0}\left[z_{r}(t)-z\right] \frac{\theta\left[z_{r}(t)\right]}{\theta_{r}} .
$$

(see [12,23]; for specific details on the mathematical derivations). In equation (3) $\theta_{r}$ represents the irre- 
ducible water content. Summarizing, the concentration $C(z, t)$ is calculated from water content pattern. To determine the water content, one can apply numerical methods to solving the complete flow equation (see [17]). The alternative approach is to derive an approximate, analytical solution for water content distribution which, in turn, permits one to calculate the solute concentration in a closed form. The motivation of introducing approximations in the flow is that inaccuracy in water content distribution due to the adopted assumptions will have a small effect on the concentration. Such an assumption has been validated (at least for sandy soils) both numerically (see [13]), and experimentally (see [20]).

\section{Concise review of the solution to water content during a cycle of infiltration and redistribution}

We model transport during a cycle of infiltration and redistribution. One of the main feature of such a problem is that water flow is different whether considering infiltration or redistribution. In particular, water content at the end of the infiltration will constitute the initial condition for solving redistribution. We introduce some assumptions which permit us to obtain analytical closed form for water content. The main assumption requires that gravity dominates the flow, i.e. the flow is essentially vertical.

The infiltration stage originates from the application of a specific amount of water $W$ (volume per area) at the soil surface during the time interval $t_{a p}$ with constant rate $r=W / t_{a p}$. The redistribution stage starts after the infiltration of all the applied water $W$. We do not report detailed expressions of the water content as well as flux, since they were topic of previous works [12, 22], and address to them the interested reader. For the sake of completeness we simply have sketched in Fig. 1. how the water content distribution looks.

In the infiltration stage (1a) the water content $\theta$ is constant behind the "front", and it advances at constant velocity till to $z_{f}\left(t_{i}\right)$ corresponding to the end of infiltration. Starting from this, a redistribution develops (1b), and the water content (which now is not anymore constant behind the front) moves at a reduced velocity (deceleration is discussed in detail by [23]).
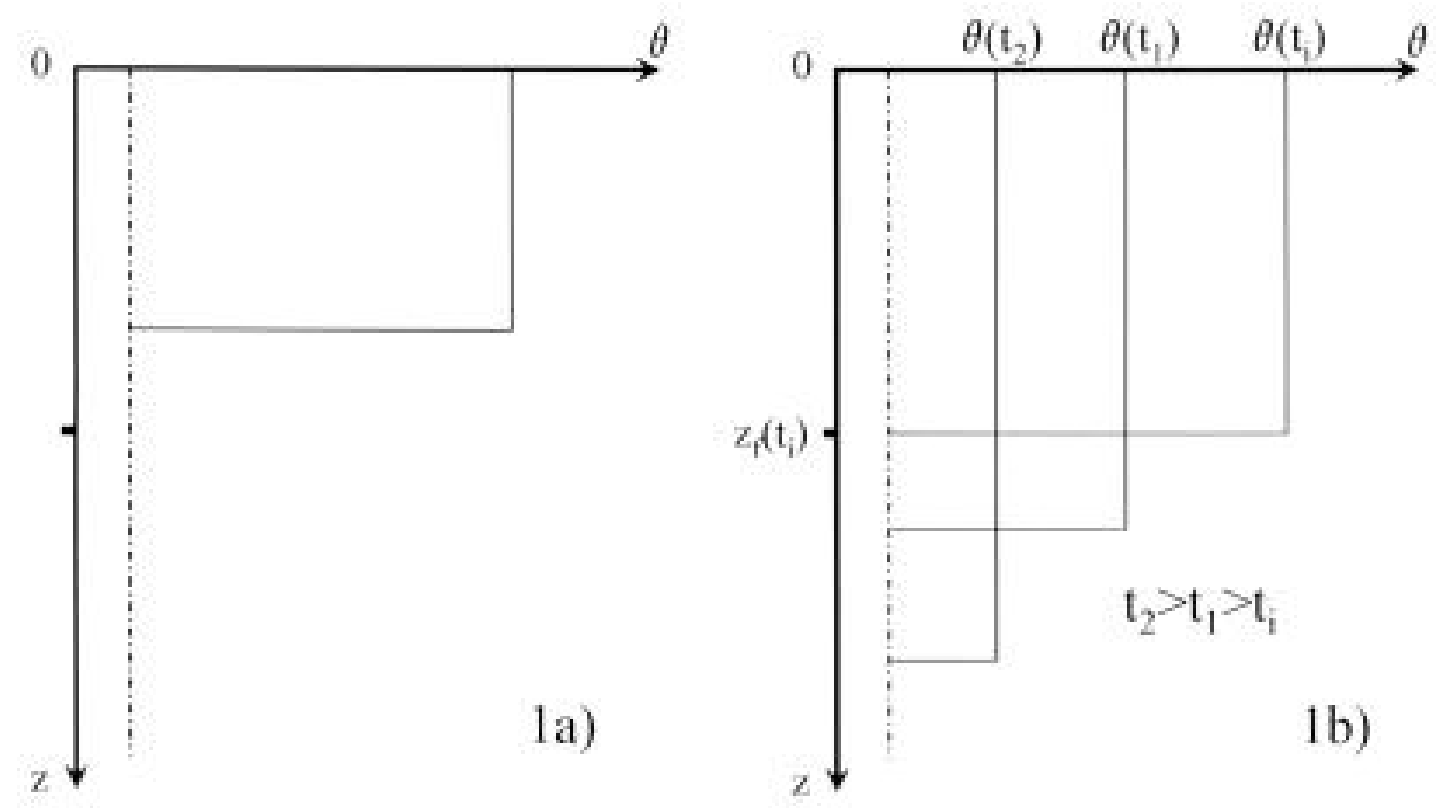

Fig. 1 - Definition sketch of the approximate local water content in the infiltration (1a), and redistribution (1b) stage.

\section{Field scale applications}

We show the applicability of our results by considering two typical problems encountered in applications. The first problem is tracking salinity distribution into a soil by applying a certain amount of water. Such a practice is sometimes needed since the high salinity degree may drastically reduce the soil fertility [14], and therefore it is customary to reduce it by flushing it. The second problem is estimating the salt leaching.
Our analytical solutions are particularly useful for modelling transport at field scale. In fact, owing to its intrinsic heterogeneity, the soil hydraulic properties are regarded as spatial random functions. Such a representation requires applying a stochastic approach to modelling flow and transport in heterogeneous soils. However, solving flow and transport stochastic equations normally demands large computational effort. Analytical solutions are of great value because they simplify such computations. We illustrate application of the one-dimensional transport model to calculate 
the mean salinity at the field scale by using the column approximation of Dagan and Bresler [4]. For vertical mean transport to a shallow depth (i.e. small compared to both field horizontal extent and heterogeneity correlation scales in the horizontal plane) stream tubes are represented by independent columns. Spatially variable properties are then modelled as stationary random functions of the horizontal coordinates. This column approximation has been tested and found useful in extensive applications under varied field conditions (e.g., $[1,7,3,20]$ ).

Although many of the input model parameters can be regarded as random, we limit the analysis by accounting for the heterogeneity of the saturated conductivity $K_{s}$ only, since it is generally regarded as determining the greatest variability [19]. The conductivity is modelled by assigning the probability density function $f\left(K_{s}\right)$. Due to its dependence on $K_{s}$, the salinity distribution derived in the previous sections (which is valid for a single column) becomes random. We are interested in computing the mean expectation over all samples of columns.

In Figures 2 and 3 we have depicted the mean saline distribution $\left\langle C^{\prime}\right\rangle$ pertinent to the situations pre-

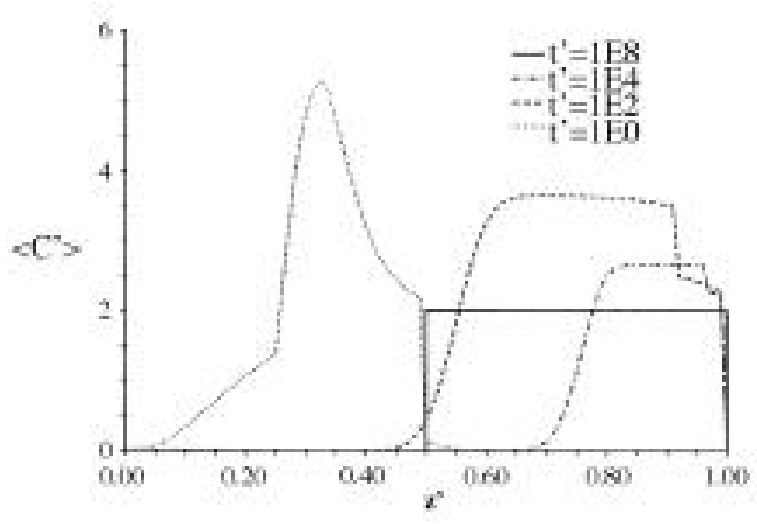

Fig. 2 - Mean (normalized) salinity distribution $\left\langle C^{\prime}\right\rangle$ corresponding to a finite pulse along the depth $z^{\prime}$, and at different times t'.

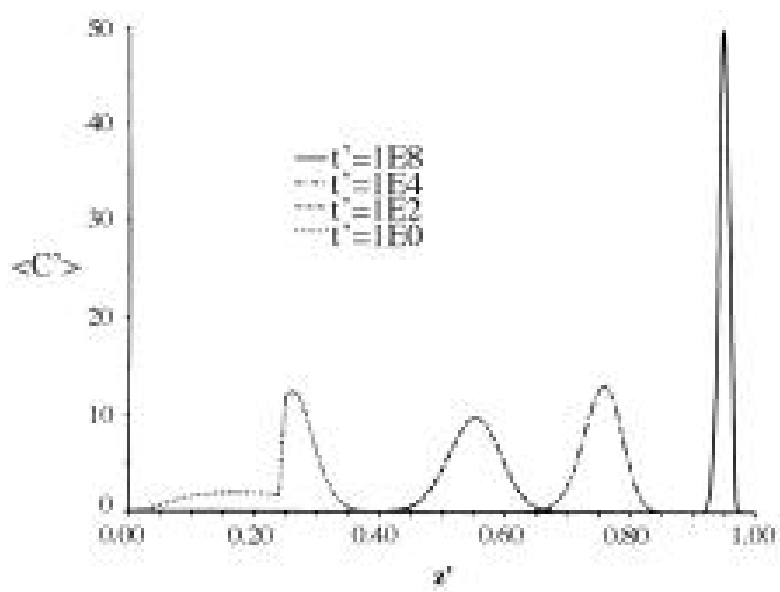

Fig. 3 - Mean (normalized) salinity distribution $\left\langle\mathrm{C}^{\prime}\right\rangle$ corresponding to a Dirac pulse along the depth z', and at different times t. viously described. At very long times $t^{\prime}=t_{a p}$ the reducing velocity drastically slows transport, and the plume approaches the asymptotic shape, that resembles "exactly" the initial configuration, at $z^{\prime}=z \theta_{r / W}[20]$. Finally, it is emphasized that our analytical results are in reasonable agreement with the Monte Carlo simulations of Lessoff and Indelman [13].

\section{Conclusions}

We present an analytic solution for advective salt distribution. The model is based on a closed solution of two - stage gravitational infiltration - redistribution into dry soils. We assume that transport is predominantly vertical. This assumption can be justified where field properties, and boundary conditions in the horizontal plane change over a scale which is large as compared to the depth-transport. The effects of capillary suction on both the lateral and horizontal flow are neglected. As such, the model is best applied to sandy soils. We also neglect the effects of local dispersion/diffusion.

Although the above assumptions are somewhat limiting, they are commonly used in the soil literature on empirical grounds [6]. This solution is useful to interpret laboratory data and calibrate numerical models. Furthermore, subject to the above limiting assumptions, our results allow to predict the salinization of soils in dry conditions.

\section{References}

[1] Bresler E., Dagan G., Convective and pore scale dispersive solute transport in unsaturated heterogeneous fields, Water Resour. Res., (1981), 17, 16831693.

[2] Broadbridge P., White I., Constant rate rainfall infiltration: a versatile nonlinear model: 1. Analytical solution, Water Resour. Res., (1988), 24, 145-154.

[3] Comegna V., Coppola A., Sommella A., Effectiveness of equilibrium and physical nonequilibrium approaches for interpreting solute transport through undisturbed soil columns, J. Contam. Hydrol., (2001), 50, 121-138.

[4] Dagan G., Bresler E., Solute dispersion in unsaturated heterogeneous soil at field scale: I. Theory, Soil Sci. Soc. Am. J., (1979), 43, 461-467.

[5] DAGAN G., BRESLER E., Unsaturated flow in spatially variable fields: I. Derivation of models of infiltration and redistribution, Water Resour. Res., (1983), 19, 413-420.

[6] Dagan G., The Bresler-Dagan model of flow and transport: recent theoretical developments. In: Dagan G., Russo D. (Eds.), Water flow and solute transport in soils, developments and applications. Advances Series in Agricultural Sciences, vol. 20. SpringlerVerlag, Berlin, (1993), 13-32.

[7] Destouni G., Cvetrovic V., Field scale mass arrival of sorptive solute into the groundwater, Water Resour. Res., (1991), 27, 1315-1325.

[8] Ellsworth T.R., JuRY W.A., ERnSt F.F., Shouse P.J., A 3-D field study of solute transport through unsatu- 
rated layered porous media: 2. Characterization of vertical dispersion, Water Resour. Res., (1991), 27, 967-981.

[9] GARDNER W.R., Some steady state solutions of unsaturated moisture flow equations with application to evaporation from a water table, Soil Sci., (1958), 85, 228-232.

[10] Govindaraju R.S., Kavvas M.L., Jones S.E., RolSTON D.E., Use of Green-Ampt model for analyzing one-dimensional convective transport in unsaturated soils, J. Hydrol., (1996), 178, 337-385.

[11] HARTER T., ZhANG D., Water flow and solute spreading in heterogeneous soils with spatially variable water content, Water Resour. Res., (1999), 35, 415-426.

[12] Indelman P., Touber-Yasur I., Yaron B., Dagan G., Stochastic analysis of water flow and pesticides transport in a field experiment, J. Contam. Hydrol., (1998), 32, 77-97.

[13] Lessoff S.C., Indelmann P., Analytical model of solute transport by unsteady unsaturated gravitational infiltration, J. Contam Hydrol., (2004), 72, 85-107.

[14] Nachabe M.H., Islas A.L., Illangasekare T.H., Analytical solutions for water-flow and solute transport in the unsaturated zone, Ground Water, (1995), 33, 304-310.

[15] Philip J.R., KNIGHT J.H., Redistribution from plane, line, and point sources, Irrig. Sci., (1991), 12, 169180.

[16] PRotopapas A.L., Bras R.L., The one-dimensional approximation for infiltration in heterogeneous soils, Water Resour. Res.,(1991), 27, 1019-1028.

[17] Romano N., Brunone B., SAntini A., Numerical analysis of one-dimensional unsaturated flow in layered soils, Advances in Water Resources, (1998), 21, 315-324.

[18] Roth K., Jury W.A., Fluhler H., Attinger W., Transport of chloride through an unsaturated field soil, Water Resour. Res., (1991), 27, 2533-2541.

[19] Russo D., Russo I., LAUFER A., On the spatial variability of parameters of the unsaturated hydraulic conductivity, Water Resour. Res, (1997), 33, 947-956.

[20] Severino G., Santini A., Sommella A., Determining the soil hydraulic conductivity by means of a field scale internal drainage, J. Hydrology, (2003), 273, 234-248.

[21] Severino G., Indelman P., Analytical solutions for reactive transport under an infiltration-redistribution cycle, J. Contam. Hydrol., (2004), 70, 89-115.

[22] Severino G., Santini A., Un modello di trasporto di pesticidi in suoli eterogenei, Riv. di Ing. Agr., (2004), 2, 33-42.

[23] Severino G., Monetti V.M., Santini A., Toraldo G., Unsaturated Transport with Linear Kinetic Sorption Under Unsteady Vertical Flow, Trasport in Porous Media, (2005).

[24] Yeh T.C., Gelhar L.W., GutJahr A.L., Stochastic analysis of unsaturated flow in heterogeneous soils: 1 statistically isotropic media, Water Resour. Res., (1985a), 21, 447-456.

[25] Yeh T.C., Gelhar L.W., Gutjahr A.L., Stochastic analysis of unsaturated flow in heterogeneous soils: 2 statistically anisotropic media with variable alpha, Water Resour. Res., (1985b), 21, 457-464.

\section{SUMMARY}

The behaviour of soil salinity in dry conditions is investigated by means of analytical tools. We present a closed solution for advective transport, and apply it to two typical real-world scenarios: i) a finite depthdistributed (i.e. Heaviside-type), and ii) an instantaneous top-surface broadcasted (i.e. Dirac-type) saline pulse. Our analytical solution is then incorporated into a stochastic stream tube model to compute the mean salinity profile in a heterogeneous field. An unusual phenomenon of plume contraction is observed when the soil is getting drier and drier (typically at long times during a water redistribution period). It is emphasized that our results are in agreement with previous analytical studies (see e.g. [22,23,24]), and match quite well synthetic as well as real data provided that sandy soils are dealt with.

Key words: salinity, soil, analytical solutions, heterogeneity. 